\title{
Angiotensin converting enzyme inhibitors in heart failure: how good are they?
}

\footnotetext{
Department of Cardiovascular Medicine, University of Birmingham, Queen Elizabeth Hospital, Edgbaston, Birmingham J N Townend W A Littler Correspondence to Prof W A Littler Department of Cardiovascular Medicine, University of Birmingham, Queen Elizabeth Hospital, Edgbaston, Birmingham B15 2TH.

Accepted for publication 11 May 1992
}

\author{
J N Townend, W A Littler
}

The natural history of heart failure is one of relentless deterioration to an early death. Despite giving symptomatic relief, diuretics and digoxin have not been shown to affect the progessive nature of the syndrome. Three large independent trials showed that the addition of an angiotensin converting enzyme (ACE) inhibitor to the therapeutic regimen reduced mortality in patients with moderate or severe heart failure. ${ }^{1-3}$ Several studies have also showed that ACE inhibitors improve symptoms and exercise tolerance. ${ }^{4-13}$ As a result ACE inhibitors have become a routine part of the treatment of heart failure, indeed it is now widely considered unethical to perform placebo controlled studies of these agents. However, it is difficult to extrapolate information gained from clinical trials to individual patients. Close scrutiny of the data reveals more modest benefits than are apparent from the "headline" results.

\section{Mortality}

The CONSENSUS study showed that treatment with enalapril caused a $40 \%$ reduction in mortality at six months, from $44 \%$ in the placebo group to $26 \%$ in the treatment group in a population of 253 patients with New York Heart Association (NYHA) class IV symptoms. ${ }^{1}$ The patient group was elderly (mean age over 70 years) and was on established treatment with large doses of diuretics. By the end of the study (mean period of follow up patients assigned to enalapril only 215 days) $50(39 \%)$ of the initial 127 patients treated with enalapril had died. No information has been published subsequently on the longer term results of this trial. Looking at the average increase in life expectancy given to a patient in class IV heart failure by the addition of enalapril is salutary-the interval between the two mortality curves suggests a figure of approximately 20 weeks. Patients with NYHA class IV symptoms have such a poor quality of life that it may be argued that unless symptoms improve considerably, the addition of a few months to life expectancy is no great gain unless it is as a bridge to cardiac transplantation. Symptomatic status was measured in the CONSENSUS study as physician determined changes in NYHA functional class, a rather crude and subjective assessment. There was a significant difference in favour of enalapril: $54(42 \%)$ of 127 of patients on active treatment improved their NYHA classification compared with $27(22 \%)$ of 126 of those on placebo. However, over half $(56 \%)$ of the patients treated with enalapril did not improve: they died or continued in NYHA functional class IV.

In the Studies of Left Ventricular Dysfunction (SOLVD) treatment study the risk of death was reduced by $16 \%$ after a mean treatment period of 41 months in 2569 patients with mainly moderate heart failure (over $90 \%$ were in NYHA class II and III). ${ }^{2}$ In the treatment group $452(35.2 \%)$ out of 1285 patients died during follow up compared with $510(39.7 \%)$ out of 1284 patients assigned to placebo. Although at first sight the figures seem less impressive than those of the CONSENSUS study, the mean increase in life expectancy for a patient treated with enalapril was six to eight months compared with about five months in the CONSENSUS study. Because most patients seen in everyday clinical practice are in class II and III heart failure the SOLVD data may be of more direct clinical relevance. Nevertheless, several criticisms may be made of the study. Only $6.4 \%$ of nearly 40000 patients with ejection fractions of less than $35 \%$ were included in the treatment study, raising doubts about the applicability of these data to the patients seen in everyday practice. In particular $12 \%$ of patients were excluded because of "cardiovascular" problems and a total of $38 \%$ were excluded for reasons of "administration", coexistent disease, and "other" problems. Patients unable to tolerate the drug or its withdrawal were excluded in a run-in phase, which may have affected the results in either direction. By the end of the study over $30 \%$ of the patients treated with enalapril and over $40 \%$ of those taking placebo had stopped taking blinded medication while the use of open label ACE inhibitors was quite common (23\% and $14 \%$ in the placebo and enalapril groups respectively at three years). Also about $50 \%$ of the patients were taking vasodilators (mainly nitrates) other than ACE inhibitors throughout the trial period.

The second Vasodilator Heart Failure Trial (V-HeFT II) study compared direct-acting vasodilators (a combination of hydralazine and isosorbide dinitrate in high doses) with enalapril in a group of 804 men with heart 


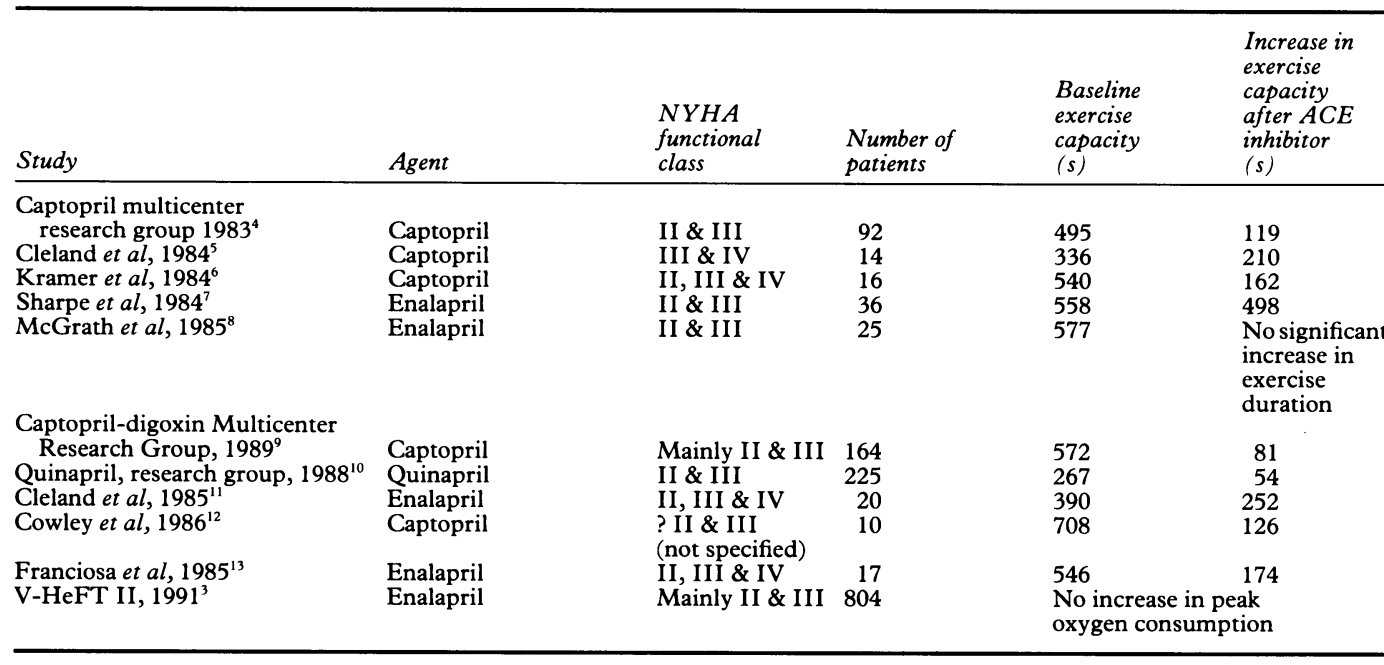

*This is not an exhaustive list.

failure (predominantly NYHA class II and III). ${ }^{3}$ Overall mortality (mean duration of follow up 2.5 years, range 6 months to 5.7 years) was not significantly different in the two groups, with 132 deaths in the 403 patients assigned to enalapril and 153 deaths in those patients receiving the hydralazine/nitrate combination. Cumulative mortality at two years was significantly lower in the enalapril group than in the hydralazine/nitrate group (18\% v $25 \%$ respectively). By four years, however, the cumulative mortality of the patients assigned to enalapril was $42 \%$. No women were included in the study and only half the patients had heart failure caused by coronary artery disease. This unusually low proportion with coronary artery disease may have tended to reduce overall mortality because this aetiology is said to carry an adverse prognosis in patients with heart failure. ${ }^{14}$ Over a third of patients were said at baseline to use alcohol excessively with no comment made on its subsequent use or discontinuation.

Thus the $16-31 \%$ reduction in one year mortality (depending on functional class) with ACE inhibitors represents a slowing rather than a halting of disease progression. The life expectancy of patients with heart failure remains considerably shortened. It is perhaps of much more importance therefore, to determine whether these agents improve the quality of remaining life. Surrogates for clinical improvement such as exercise tolerance have been looked at in numerous, but usually small, controlled trials.

\section{Quality of life}

Although many of the results do show statistically significant increases in exercise tolerance the figures are very variable and the absolute increases are often small (see table). The captopril multicentre research group report ${ }^{4}$ is perhaps representative, with a $24 \%$ improvement in treadmill exercise tolerance actually reflecting a 2 minute increase in exercise time to a mean maximum value of only 614 seconds. Such figures are heavily dependent on the exercise protocol chosen and it is difficult to extrapolate improvements in incremental exercise protocols to everyday activity. Although it was only a secondary end point in the V-HeFT II trial, exercise capacity was measured by determining peak oxygen consumption during incremental bicycle ergometry. This represents the largest single study of the effect of an ACE inhibitor on exercise capacity. In contrast to the hydralazine-nitrate combination which produced a small $(<1 \mathrm{ml} / \mathrm{kg} / \mathrm{min})$ increase in peak oxygen consumption, enalapril did not increase peak oxygen consumption at any of the time points examined during follow up. Other reports on the effect of ACE inhibitors on oxygen uptake during exercise, a more objective and reproducible index of exercise tolerance than simple exercise duration, ${ }^{15}$ have given variable results. Franciosa et $a l^{13}$ found both oxygen consumption and treadmill exercise tolerance were increased significantly by enalapril in comparison to placebo while Cowley et al ${ }^{12}$ showed that although treadmill exercise duration was significantly increased by captopril there was no change in oxygen consumption.

The need for hospital admission can also be used as an index of the quality of life of chronically sick patients. Once again the results are disappointing. Although significantly reduced compared with placebo $(47.7 v 57.3 \%$ over a study period of almost four years) the rates of hospital admission during treatment with ACE inhibitors in the SOLVD study are depressingly high. During the study 613 of 1285 patients treated with enalapril required 971 hospital admissions for congestive heart failure.

Functional status and quality of life were examined as part of the SOLVD treatment study and the preliminary results were reported recently. ${ }^{16}$ The NYHA functional class determined by a physician at one year remained unchanged or improved in slightly but significantly more $(74 \%)$ of the patients given enalapril than those given placebo $(66 \%)$. A self administered questionnaire, however, 
showed that patients perceived improvements only in "social functioning" at six weeks and one year and in "general health" at six weeks only. There were no significant differences between the two groups with respect to heart failure symptoms, activities of daily living, depression, and general life satisfaction at any point during follow up. The results of a more detailed study of a sample group of the SOLVD population are awaited.

Angiotensin converting enzyme inhibitors in combination with diuretic treatment are the best available medical treatment for heart failure. In all the trials described patients were on established diuretic treatment. Single agent treatment of heart failure with ACE inhibitors is ineffective $e^{17}$ and it cannot be excluded that much of the beneficial effect of ACE inhibitors in heart failure may be the result of a reduction of the adverse haemodynamic and neurohormonal effects of diuretic therapy. Direct acting vasodilators in high dose are a more cumbersome and less well tolerated regimen but may be superior in their capacity to improve exercise tolerance. Neither ACE inhibitors nor any other medical treatment come close to the prognostic and symptomatic improvement that can be gained by cardiac transplantation. ${ }^{18}$ Organ availability unfortunately precludes more widespread use of this highly successful treatment. ACE inhibitors are undoubtedly an advance and their modest efficacy contrasts with the disappointing results obtained from trials of inotropes (both $\beta$ agonists and phosphodiesterase inhibitors, ${ }^{19} 20$ ) calcium antagonists, ${ }^{21}$ and vasodilators such as hydralazine, ${ }^{22}$ and prazosin. ${ }^{23}$ However, they are a limited advance and other treatments, both pharmacological and perhaps biomechanical, are needed to improve significantly the lot of patients with this disabling and progressive condition.

JNT is a British Heart Foundation junior research fellow.

1 The CONSENSUS Trial Study Group. Effects of enalapril on mortality in severe congestive heart failure. Results of the Cooperative North Scandinavian Enalapril Survival Study(CONSENSUS). N Engl J Med 1987;316:1429-35. 2 The SOLVD investigators. Effect of enalapril on survival in patients with reduced left ventricular ejection fractions and congestive heart failure $N$ Engl $J$ Med 1991;325: 293-302.

3 Cohn JN, Johnson G, Ziesche S, et al. A comparison of enalapril with hydralazine-isosorbide dinitrate in the treatment of congestive heart failure. $N$ Engl J Med 1991;325:303-10.

4 Captopril Multicenter Research Group. A placebo controlled trial of captopril in refractory chronic congestive heart failure. J Am Coll Cardiol 1983;2:755-63.

5 Cleland JGF, Dargie HJ, Hodsman GP, Ball SG, Roberson JIS, Morton JJ, East BW, Robertson I, Murray GD, Gillen G. Captopril in heart failure. A double blind controlled trial. Br Heart J 1984;52:530-35.

6 Kramer BL, Massie BM, Topic N. Controlled trial of captopril in chronic heart failure: a rest and exercise captopril in chronic heart failure: a rest and ex

7 Sharpe DN, Murphy J, Coxon R, Hannan SF. Enalapril in patients with chronic heart failure: a placebo-controlled randomized, double blind study. Circulation 1984;70. 271-8

8 McGrath BP, Arnolda L, Matthews PG, Jackson B, Jennings $G$, Kiat $H$, Johnston CI. Controlled trial of enalapri in congestive cardiac failure. Br Heart $J$ 1985;54:405-14.

9 The Captopril-Digoxin Multicenter Research Group. Comparative effects of therapy with captopril and digoxin in patients with mild to moderate heart failure. JAMA 1988;259:539-44.

10 Riegger GAJ. Effects of quinapril on exercise tolerance in patients with mild to moderate heart failure. Eur Heart $J$ patients with mild

11 Cleland JGF, Dargie HJ, Ball SG, et al. Effects of enalapril in heart failure: a double blind study of effects on exercise heart failure: a double blind study of effects on exercise performance, renal function, hor
state. Br Heart J 1985;54:305-12.

12 Cowley AJ, Stainer K, Rowley JM, Hampton JR. Effects of captopril on abnormalities of the peripheral circulation and respiratory function in patients with severe hear failure. Lancet 1984;ii:1120-4.

13 Franciosa JA, Wilen MM, Jordan RA. Effects of enalapril, a new angiotensin converting enzyme inhibitor, in a controlled trial in heart failure. J Am Coll Cardiol 1985;5: $101-7$.

14 Likoff MJ, Chandler SL, Kay HR. Clinical determinants of mortality in chronic congestive heart failure secondary to idiopathic dilated or to ischaemic cardiomyopathy. $A m$ Cardiol 1987;59:634-8.

15 Cohen-Solal A, Zannand F, Kayanakis JG, Gueret P, Aupetit JF, Kolsky H. Multicentre study of the determinants of peak oxygen uptake and ventilatory threshold ants of peak oxygen uptake and ventilatory threshold during bicycle exercis

16 Rogers WJ. Functional status and quality of life of 2569 patients with symptomatic CHF randomized between enalapril and placebo in the studies of left ventricular dysfunction (SOLVD) treatment tria [abstract]. Circulation 1991;84(suppl II):311.

17 Anand IS, Kalra GS, Ferrari R, Wahi PL, Harris PC, PooleWilson PW. Enalapril as initial and sole treatment in severe chronic heart failure with sodium retention. Int $J$ Cardiol 1990;28:341-6.

18 Kriett JM, Kaye MP. The registry of the international society for heart transplantation: seventh official report. $J$ Heart Transplant 1990;9:323-30.

19 Colucci WS, Alexander RW, Williams GH, et al. Decreased lymphocyte beta-adrenergic-receptor density in patients with heart failure and tolerance to the beta-adrenergic with heart failure and tolerance to the beta-adren
agonist pirbuterol. $N$ Engl J Med 1981;305:185-90.

20 Packer M, Carver JR, Rodeheffer RJ, et al. Effect of oral milrinone on mortality in severe chronic heart failure. $N$ Engl J Med 1991;325:1468-75.

21 Calcium antagonist caution. Lancet 1991;337:885-6.

22 Franciosa JA, Weber KT, Levine TB. Hydralazine in the long term treatment of chronic heart failure: lack of difference from placebo. Am Heart J 1982;104:587-94.

23 Cohn JN, Archibald DG, Ziesche S, et al. Effect of vasodilator therapy on mortality in chronic congestive heart failure: results of a Veterans Administration Cooperative Study. N Engl J Med 1986;341:1547-52. 